\title{
A EFICIÊNCIA DOS GASTOS PÚBLICOS EM EDUCAÇÃO: EVIDÊNCIAS GEORREFERENCIADAS NOS MUNICÍPIOS GOIANOS
}

\author{
Carlos Rosano-Peña * \\ Pedro Henrique Melo Albuguerque ${ }^{\dagger}$ \\ Carvalho Jose Marcio ${ }^{\ddagger}$
}

\begin{abstract}
Resumo
Este artigo busca avaliar a eficiência dos gastos públicos em educação nos municípios goianos. A eficiência das redes municipais no período 2005-2009 foi avaliada através da comparação dos resultados obtidos no modelo de Análise Envoltória de Dados clássico com os calculados pelo método da fronteira invertida. Os resultados revelam o nível de ineficiência $(67,44 \%)$ e suas causas: a) ineficiência de escala $(11,63 \%), b)$ impacto do entorno $(4,01 \%)$, c) ineficiência de gestão $(16,92 \%)$. Este trabalho ainda estima e georreferência o custo da ineficiência e os municípios que conseguiram alcançar o desempenho mais equilibrado.
\end{abstract}

Palavras-chave: Eficiência escolar, Impacto do Entorno Escola, Análise Envoltória de Dados, Fronteira Invertida.

\begin{abstract}
This paper is aimed at evaluating the efficiency of public spending on education in the municipalities of Goiás State. The efficiency of municipal networks in the period 2005-2009 was evaluated by comparing the results obtained in the model of Data Envelopment Analysis (DEA) with those calculated by the classic method of inverted frontier. The results reveal the level of inefficiency $(67.44 \%)$ and its causes: a) scale inefficiency $(11.63 \%), b)$ the impact of the environment $(4.01 \%), c)$ inefficiency of management $(16.92 \%)$. This paper also estimates and locate geographically the cost of inefficiency and the municipalities that have achieved more balanced performance.
\end{abstract}

Keywords: School efficiency, Impact of school environment, Data Envelopment Analysis, Reversed Frontier.

JEL classification: I20

\footnotetext{
* Universidade de Brasília. Departamento de Administração. E-mail: gmcrosano@gmail.com

† Universidade de Brasília. Departamento de Administração. E-mail: pedro.melo.albuquerque@gmail.com

‡ Universidade de Brasília. Departamento de Administração. E-mail: jmcarvalho@unb.br
} 


\section{Introdução}

Uma educação elitizada favorece as classes sociais privilegiadas, de modo que a escola se consolida como um sistema que reproduz o anacronismo, a concentração de renda e a exclusão social. Quando desenvolvida de forma universal e com qualidade, ela reverte o círculo vicioso de pobreza e fundamenta a expansão e entendimento dos direitos civis e políticos (Carvalho 2002). Assim, a educação se constitui em um aspecto crucial para o desenvolvimento econômico do país, para o aprimoramento do exercício da democracia e da cidadania, para a redução da criminalidade, bem como para a queda da mortalidade infantil e o aumento da expectativa de vida (Franco 2008). Hoje já é amplamente aceita a ideia de que uma alta escolaridade média é a maior vantagem comparativa dos países, das empresas e dos indivíduos para enfrentar a crescente competitividade, a intensificação da globalização, a acelerada mudança das bases tecnológicas e as incertezas do desenvolvimento futuro.

Diante desta realidade, o Brasil vem alocando crescentes quantias de recursos humanos e orçamentários na educação convencional, bem como atacando o grave problema da baixa escolaridade média e do analfabetismo da população de 15 anos ou mais. Segundo o Censo Escolar (INEP 2009a), de 708.793 docentes com ensino superior completo no ensino fundamental em 1999 passouse para 1.015 .061 em 2009, representando um aumento de 43,2\%. A partir da regulamentação do Fundo de Manutenção e Desenvolvimento do Ensino Fundamental e de Valorização do Magistério (FUNDEF - Lei No 9.424/96) - que estabelece maior equidade na distribuição dos recursos e condições efetivas para a recuperação dos salários dos professores e para o resgate do prestígio social da carreira - os gastos em educação fundamental dos estados e municípios passaram a consumir mais de $15 \%$ da crescente receita de tributos e transferências. Além dessas fontes, recursos são transferidos através de programas federais suplementares e complementares, dentre os quais pode se encontrar o Programa de Livros Didáticos, o Programa Nacional de Alimentação Escolar, o Programa Nacional de Apoio ao Transporte Escolar, o Programa Dinheiro Direito na Escola. Conforme dados do INEP (2009b), a taxa de crescimento real do investimento público direto em educação fundamental por estudante foi de $9,5 \%$ ao ano entre 2000 e 2009. Neste período, o gasto real médio por aluno passou de $\mathrm{R} \$ 1.523$ para $\mathrm{R} \$ 3.245$.

Não é pequeno o progresso ou retorno desses investimentos. Basta lembrar que por muito tempo o ingresso na escola foi limitado às classes mais privilegiadas. Hoje, segundo a (UNICEF 2009), a universalização (entendida como extensão das oportunidades de acesso à escola a todos) do Ensino Fundamental está praticamente consolidada, chegando a aproximadamente $97,6 \%$ das crianças e adolescentes entre 7 e 14 anos. Nos resultados do Programa Internacional de Avaliação de Alunos, PISA-2009 OECD (2010), uma pesquisa trienal de conhecimentos e competências de estudantes na faixa dos 15 anos de idade, o Brasil aparece entre os três países que mais evoluíram na educação na década.

Mesmo reconhecendo-se as melhorias dos últimos anos, o ensino fundamental vem sendo bastante questionado quanto à sua qualidade e eficiência. O PISA-2009 evidencia que a qualidade da educação brasileira encontra-se aquém dos indicadores obtidos pelo conjunto de países desenvolvidos ou em desenvolvimento amostrados. O Brasil está atrás de países como Coreia do Sul, Hong Kong, Cingapura, Tailândia ou mesmo de países latino-americanos 
como o Chile, o Uruguai, o México e a Colômbia, ocupando a a 53a colocação entre os 65 países pesquisados. Nas avaliações nacionais, o Sistema de Avaliação da Educação Básica (SAEB) revela que essa situação é ainda mais dramática quando se considera indicadores como as taxas de repetência, abandono, distorção idade/série e as desigualdades regionais no ensino público.

Portanto, a grande questão que se coloca agora é como elevar a qualidade do ensino nas escolas públicas brasileiras, particularmente em um contexto de escassez e maior necessidade de racionalidade e eficiência na utilização dos recursos disponíveis.

Este artigo busca examinar e georreferenciar a eficiência dos gastos públicos em educação dos municípios goianos, empregando o método Análise Envoltória de Dados e mapas produzidos em ambiente SIG (Sistema de Informação Geográfica).

Acredita-se que com a ajuda desses métodos e seus resultados, os gestores das redes municipais terão à sua disposição um ferramental capaz de auxiliálos tanto no processo de tomada de decisão, quanto no debate do aperfeiçoamento de seu principal problema econômico: o conflito entre as múltiplas necessidades e a insuficiência dos recursos disponíveis.

Além deste preâmbulo, o presente trabalho está estruturado da seguinte forma: na seção 2, é oferecida uma revisão da literatura sobre a eficiência da educação, na seção 3 descrevem-se os métodos DEA-clássicos, os procedimentos para identificar e isolar o impacto na eficiência das variáveis não controláveis e o método da fronteira invertida. Na seção 4 são descritos os parâmetros do problema. A seção 5 mostra os resultados da pesquisa e finalmente, na seção 6, apresentam-se as principais conclusões do trabalho.

\section{Revisão da Literatura}

A partir da década de 1960, e mais intensamente nas últimas décadas, pôde-se observar um crescente número de publicações que tinham por objetivo, medir o desempenho dos sistemas educacionais, utilizando os métodos paramétricos e não-paramétricos para estimar a função de produção ou fronteira eficiente da educação.

Inicialmente a abordagem da função produção na educação foi utilizada por Coleman (1966a), que a partir de uma regressão múltipla buscaram verificar se o desempenho dos alunos afro-americanos, aquém do esperado, estava relacionado a uma insuficiência de recursos em suas escolas. Outra publicação clássica nessa linha de pesquisa corresponde a Hanushek \& Luque (2002). Neste último trabalho foram analisadas 147 estimativas da função paramétrica de produção, onde se deduz que a forma geral da função é dada pela equação $y=F(c, m, g, p, s)$, em que $y$ denota o desempenho dos alunos, o qual pode depender de uma série de fatores, agrupados em cinco categorias: características pessoais do aluno $(c)$, tais como raça e gênero; características de sua família $(m)$, tais como renda ou outra medida de seu nível socioeconômico; características de seus colegas na escola $(g)$; características dos seus professores $(p)$, tais como escolaridade, salário ou experiência; e outras características escolares $(s)$. As conclusões desses estudos indicam que nem o nível de gastos por estudante, nem o nível de formação de professores tem efeitos significativos sobre o rendimento escolar e que as características do entorno familiar parecem ser mais significantes. Argumenta-se que a causa básica do desem- 
penho inadequado é estrutural e organizacional, não financeira. Esse entendimento se destaca na literatura internacional e está em consonância com os resultados de pesquisas realizadas no Brasil por Diaz (2007), Menezes-Filho (2007), Ferraz et al. (2009) entre outros.

Um estudo similar mais abrangente é relatado em Education at a Glance 2007 da OCDE (OECD 2007) que avalia a relação existente entre os gastos por aluno e desempenho dos estudantes dos países que participaram do PISA2003. O relatório conclui que mesmo que maiores níveis de investimento por aluno estejam associados à melhor desempenho, essa relação explica apenas $15 \%$ das variações nos países da OCDE, além de ressaltar que o mais importante é o modo como esses recursos são gastos.

Outra maneira de obtenção de uma fronteira eficiente é a estimação não paramétrica. A primeira experiência foi produto de um estudo da eficiência de unidades escolares nos EUA e atribuído a Charnes, Cooper e Rhodes. Eles nomearam esse método como Análise Envoltória de Dados (Data Envelopment Analysis -DEA) com a publicação do primeiro artigo no European Journal of Operations Research em 1978.

O DEA pode contemplar múltiplos insumos e múltiplos produtos medidos em diferentes unidades, o que possibilita modelar melhor a complexidade dos sistemas educacionais. Para enfrentar essa complexidade, Vinod (1976) e Gyimah-Brempong \& Gyapong (1991) utilizaram uma abordagem paramétrica por meio da análise de regressão canônica, a qual determina uma combinação linear para cada grupo de variáveis (produtos e insumos) maximizando a correlação entre os dois grupos. Essa aplicação, no entanto, como argumenta Ruggiero (1996), parte do pressuposto de que as unidades escolares são eficientes. Se essa hipótese não é válida, as estimativas dos parâmetros podem ser tendenciosas.

Nesse sentido, a fronteira DEA é definida de uma forma mais indutiva, por meio do conjunto de todos os processos produtivos tecnologicamente factíveis, estimada a partir das unidades empiricamente observadas, e delimitada pelas melhores práticas. Portanto, o método dispensa a tradicional hipótese paramétrica de comportamento eficiente das unidades analisadas, muito importante para o setor público, uma vez que neste não existe o mecanismo de liquidação automática que expulsa os produtores ineficientes, conforme acontece com o mecanismo de falência da empresa privada (Pedraja-Chaparro \& Suárez-Pandiello 2001).

O DEA tem outras vantagens. Não assume hipóteses diretas sobre o comportamento (distribuição probabilística) das variáveis e não requer a priori a especificação de nenhuma relação funcional entre os insumos e produtos para determinar sua fronteira eficiente, ficando livre dos possíveis erros decorrentes dessa especificação. O DEA determina as mudanças necessárias para que as unidades ineficientes se tornem eficientes e apresenta várias soluções que possibilitam aperfeiçoar a eficiência de uma forma mais flexível. O método também pode ser utilizado na identificação de ociosidades e folgas e na formulação de políticas de redução de insumos associada a investimentos que otimizem a eficiência e o porte ideal das unidades. Além disso, adaptações do DEA, idealizadas por Fried \& Lovell (1996), Fried et al. (1999) e Fried et al. (2002), permitem determinar o possível impacto de variáveis não controláveis (como por exemplo, o entorno escolar) e isolá-lo para uma avaliação mais justa da gestão.

Isso explica o grande sucesso do método DEA no estudo da eficiência de 
instituições de ensino e de outros setores, especialmente em organizações públicas e sem fins lucrativos. No âmbito internacional, alguns exemplos da extensa aplicação do DEA na educação são encontrados em Fare et al. (2006), Portela \& Thanassoulis (2001), Ruggiero (2006), Muniz (2002). No âmbito nacional, utilizaram o DEA os trabalhos de Marinho et al. (1997) e Façanha \& Marinho $(1999,2001)$, aplicados às instituições do ensino superior; de Gasparini \& Ramos (2003), sobre a efetividade e eficiência, por estados, no ensino médio brasileiro; Sousa \& Stosic (2005), acerca da eficiência dos gastos públicos municipais em geral; Faria \& Januzzi (2006), a respeito da eficiência de gastos na área de educação e saúde dos municípios do Rio de Janeiro; e Delgado \& Machado (2007), em trabalho que se concentra na eficiência das escolas públicas de Minas Gerais. As conclusões desses estudos, em geral, indicam que recursos extras só são viáveis quando são usados de forma eficiente e inovadora.

Uma importante compilação bibliográfica sobre o DEA e suas aplicações empíricas vem sendo atualizada na página http://www.deazone.com por Ali Emrouznejad. Porém, apesar do extenso levantamento realizado, nenhuma referencia da utilização desse método no estudo da eficiência da educação goiana foi encontrado.

Uma revisão geral da literatura sobre a eficiência no âmbito educacional é dada por Worthington (2001). Daí e até onde se sabe, é evidente que não existe um consenso sobre qual dos dois métodos (paramétrico ou DEA) é o mais adequado na educação. A escolha do método depende de fatores como: a peculiaridade da função produção a ser representada, a disponibilidade dos dados e o objeto de estudo. Contudo, segundo Álvarez (2001, p. 32), geralmente, o método não paramétrico já supera o número de pesquisas que usam os métodos paramétricos, mesmo reconhecendo-se que a fronteira DEA é muito suscetível às observações extremas, além de ignorar as perturbações aleatórias do processo produtivo.

Dentre as técnicas mais utilizadas para determinar a fronteira eficiente e os níveis de eficiência de unidades escolares, utilizou-se neste trabalho, o DEA.

\section{Análise envoltória de dados}

O DEA parte da definição de eficiência. Isso ocorre quando uma unidade produtiva atinge o nível máximo de Produtividade Total dos Fatores (PTF), definida como o quociente entre a soma ponderada dos $m$ produtos produzidos $(y)$ e a soma ponderada dos $n$ insumos utilizados $(x)$ :

$$
P T F=\frac{\sum u_{r} y_{r}}{\sum v_{i} x_{i}}
$$

em que $u_{r} \in \mathfrak{K e}^{m}$ e $v_{i} \in \mathfrak{K e}^{n}$ são as respectivas ponderações que permitem criar o valor agregado dos $y$ e $x$. O conjunto ótimo de ponderadores $u_{r}, v_{i}$ é derivado no DEA por meio de um problema de programação linear (PPL). O índice de eficiência DEA é obtido por meio da comparação de uma unidade produtiva com as unidades eficientes que formam a fronteira eficiente e atingem o nível máximo PTF, ou seja, a partir da distância que separa essa unidade da fronteira eficiente. 
Inicialmente, o modelo DEA proposto por Charnes et al. (1979) e designado por $C C R$, foi desenhado para uma análise com retornos constantes de escala. Posteriormente, foi estendido por Banker et al. (1984) para incluir retornos variáveis de escala e passou a ser chamado de BCC. Cada um desses dois modelos clássicos pode ser construído sob duas formas básicas de maximização da eficiência: 1. Reduzir o consumo de insumos, mantendo o nível de produção, ou seja, orientado ao insumo. 2. Aumentar a produção, dados os níveis de insumos, ou seja, orientado ao produto.

A única diferença entre os modelos CCR e BCC é o fator de escala que aparece apenas no modelo $B C C$. Assim, o índice do modelo $C C R$, chamado de eficiência técnica global ou eficiência produtiva $(E P)$, capta a ineficiência técnica quando não se lograr a máxima produtividade, mas também incorpora o possível efeito de um inadequado porte das unidades de produção, ou seja, $E P$ pode ser de origem tanto pura quanto de escala e, por conseguinte, para uma unidade ser $C C R$ eficiente, ela precisa ter eficiência técnica $(E T)$ e de escala $(E E)$. O modelo $B C C$ com a introdução do fator de escala permite isolar a parte da ineficiência produtiva que se deve à ineficiência técnica no sentido estrito $(E T)$, eliminando o componente devido a um porte de produção inadequado. A distância existente entre as fronteiras $C C R=E P$ e $B C C=E T$ identifica a ineficiência de escala: $E E=\frac{E P}{E T}$.

A formulação apresentada em (1) mostra o PPL para o modelo BCC-OO, orientado aos produtos. Esse problema, resolvido para cada uma das unidades da amostra, pode ser apresentado considerando $N$ unidades, produzindo $m$ tipos de produtos $y$, a partir de $n$ tipos de insumos $x$. Assim, uma unidade o qualquer produz $y_{r o}$ quantidades de produtos, utilizando $x_{i o}$ insumos. A solução envolve a obtenção dos valores para $v_{i}, u_{r}$ - o peso específico de cada insumo $i$ e produto $r$ - e $k$ (fator de escala que informa se os retornos de escala são constantes, crescentes ou decrescentes), de tal forma que a medida de eficiência para a unidade analisada $h_{o}$ seja minimizada, sujeita à restrição de que as medidas de eficiência de todas as unidades sejam maiores ou iguais a um.

$$
\begin{gathered}
\text { Min } h_{0}=\sum_{i=1}^{n} v_{i} x_{i o}+k \\
\text { Sujeito a } \sum_{r=1}^{m} u_{r} y_{r o}=1 \\
\quad \sum_{i=1}^{n} v_{i} x_{i j}+k-\sum_{r=1}^{m} u_{r} y_{r j} \geq 0 \\
\text { para } u_{r} \geq 0, v_{i} \geq 0, k \in \mathfrak{R e} \\
i=1, \ldots, n ; r=1, \ldots, m \text { e } j=1, \ldots, N .
\end{gathered}
$$

A partir daí, a formulação determina quais são as melhores práticas observadas que tomam o valor de $\mathrm{h}=1$ ou $100 \%$ e formam a fronteira eficiente. Calcula o nível de ineficiência das outras unidades analisadas, a qual é medida a partir das posições relativas ocupadas por elas em relação à fronteira. Por exemplo, se o índice encontrado é 1,25 , sua interpretação indicará que essa unidade produtiva deverá aumentar os bens e serviços produzidos em $25 \%$ no mínimo para ser eficiente. O índice BCC-OO identifica as chamadas 
melhoras radiais e pode ser dado por $1 / h$, de tal forma que uma unidade será ineficiente se $(1 / h)<1$. As melhoras não radiais equivalem às folgas existentes nas restrições que são desigualdades.

A formulação 2 mostra o PPL para o modelo BCC-IO, orientado aos insumos.

$$
\begin{aligned}
& \text { Max } w_{0}=\sum_{r=1}^{m} u_{r} y_{r o}+k \\
& \text { Sujeito a } \sum_{i=1}^{n} v_{i} x_{i o}=1 \\
& \sum_{r=1}^{m} u_{r} y_{r j}+k-\sum_{i=1}^{n} v_{i} x_{i j} \geq 0 \\
& \text { para } u_{r} \geq 0, v_{i} \geq 0, k \in \mathfrak{R e} \\
& i=1, \ldots, n ; r=1, \ldots, m \text { e } j=1, \ldots, N .
\end{aligned}
$$

Esse modelo deve fornecer resultados equivalentes ao anterior. Apenas as unidades eficientes, com $h=1$ em 1 , alcançarão em $2 w=1$. Porém, as ineficientes apresentarão um $w<1$. Assim se $w_{0}=0,8$ isso indicará que o deverá reduzir os insumos em $20 \%$, no mínimo, para ser eficiente.

\subsection{Modelos com variáveis não controláveis na análise da eficiência}

Uma adaptação interessante dos modelos DEA para avaliação de sistemas educacionais ocorreu devido à necessidade de incluir insumos não controláveis e fatores ambientais na análise, ou seja, variáveis que intervenham e influenciem o processo produtivo, mas que não são passíveis de alterações, ou seja, não estão sob controle dos gestores.

Os insumos não controláveis e os fatores ambientais são quase indissociáveis e, embora sejam não controláveis, mostraram-se em algumas pesquisas mais importantes do que os fatores controláveis na determinação do desempenho escolar (Coleman 1966b, Albernaz et al. 2002, Menezes-Filho 2007). Com frequência na literatura essas variáveis são caracterizadas pelo textitbackground socioeconômico dos alunos (estrutura e renda familiar, escolaridade dos pais, raça, idade e sexo, dentre outros aspectos), diferenciando-as dos insumos escolares que abrangem aspectos como: a infraestrutura da escola, características dos professores e dos colegas de turma (Pontili \& Kassouf 2007, Scorzafave \& Ferreira 2011).

O modelo de Fried \& Lovell (1996), que inclui essas variáveis na análise, tem a capacidade de identificar e isolar seu impacto e simultaneamente mensurar a eficiência decorrente da gestão das variáveis controláveis, possibilitando a avaliação homogênea e equitativa das unidades. Este método é composto de três etapas. Na primeira etapa, resolve-se, por exemplo, o modelo BCC-OO (1), contemplando os insumos e produtos discricionários, sem considerar as variáveis não controláveis.

Esse procedimento fornece os índices de eficiência de cada unidade e as melhoras totais necessárias para cada insumo e produto. As melhoras identificadas (radiais e não radiais — slack total S) são decorrentes de dois fatores 
discrimináveis: a ineficiência na gestão das variáveis controláveis e a influência das variáveis não controláveis. Para isolar esses fatores, o modelo de Fried e Lovell recomenda duas alternativas metodológicas em uma segunda etapa: o método econométrico (em que o slack total dos insumos e produtos da $1^{\text {a }}$ etapa se estima em função das variáveis não controláveis) ou o DEA, que será a opção escolhida neste trabalho.

Nessa segunda etapa, recomenda-se executar o modelo BCC-OI 2 tomando o slack total de cada variável utilizada na primeira etapa como insumo e as variáveis não controláveis como produtos. O modelo é formulado para determinar para cada variável concreta de cada unidade a máxima redução possível do slack total, dados os vetores das variáveis não controláveis.

Seguindo Muniz (2001), a lógica da segunda etapa pode ser ilustrada por meio da Figura 1. O objetivo é estimar a fronteira formada pelo mínimo slack total possível para cada variável das unidades analisadas. O mínimo é explicado exclusivamente pelo efeito da variável não controlável. Esse é o caso da unidade $A$ da 1 , que tem um mínimo slack total de $S_{i x a}$. Já a unidade $B$ tem um slack maior $\left(S_{i x b}\right)$. Para detectar o excesso, $B$ será comparado com a unidade $A$, que tem o mesmo valor na variável não controlável. Assim, o slack total de $B$ pode descriminar-se em dois: o slack decorrente da ineficiência na gestão das variáveis controláveis e o slack atribuído à influência das variáveis não controláveis. Em outras palavras, no caso do mínimo slack coincidir com o valor detectado na primeira etapa, ele será explicado somente pelo efeito da variável não controlável e, no entanto, se esse mínimo for inferior ao slack total inicial, assume-se que o excesso se explica pela existência de ineficiência de gestão.

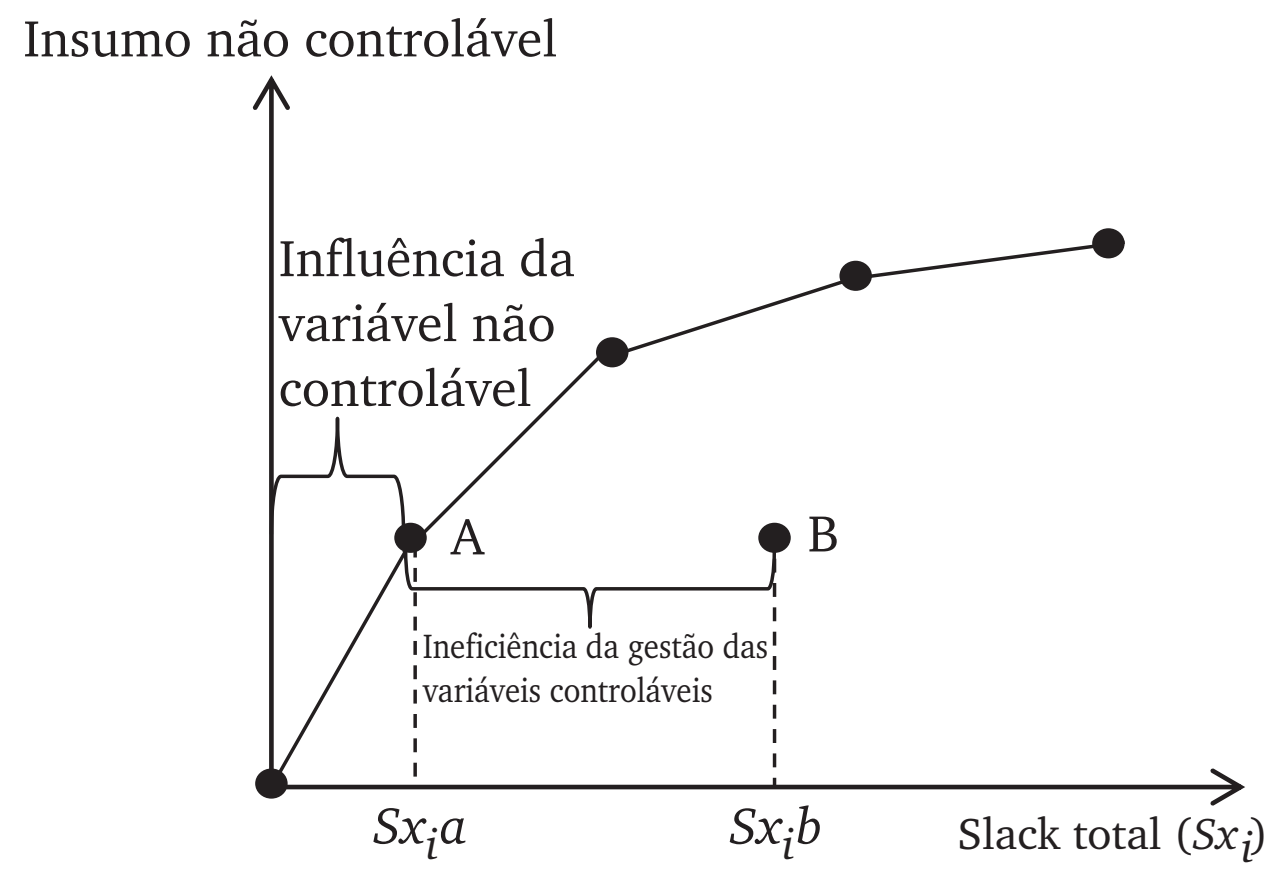

Fonte: Adaptado de Muniz (2001)

Figura 1: Decomposição do slack total na segunda etapa

Essa decomposição do slack permite o ajuste dos insumos e produtos originais das unidades ineficientes na $1^{\text {a }}$ etapa. $\mathrm{O}$ ajuste consiste em aumentar (reduzir) o valor dos produtos (insumos) das unidades na quantia correspon- 
dente ao mínimo slack atribuído aos efeitos não controláveis, o que permite compensar esse efeito exógeno. Por exemplo, no caso da unidade $B$ da Figura 1 , o ajuste em seu insumo controlável será $x_{i b}^{*}=x_{i b}-S_{x i a}$. Na terceira e última etapa, recalcula-se o modelo BCC-OO 2 da $1^{\text {a }}$ etapa com os dados corrigidos. Os índices de eficiência finais corresponderão à atuação do gestor.

\subsection{Fronteira invertida}

As restrições implícitas nos modelos DEA permitem a total flexibilidade das ponderações imputadas aos insumos e produtos. Parte-se do princípio que as unidades avaliadas podem combinar produtos e insumos diferentemente, destacando suas melhores características, suas especializações, o que deve ser tomado em consideração na hora de avaliar suas eficiências. Assim é possível a atribuição de peso nulo, marginalizando produtos ou insumos da determinação da eficiência, localizando um grande número de unidades na fronteira eficiente e reduzindo a capacidade discriminatória dos modelos.

Quando a especialização em alguns produtos em detrimento de outros, como neste trabalho, é indesejada, um dos métodos que permite uma melhor discriminação é a fronteira invertida.

O método de fronteira invertida, segundo Soares de Mello et al. (2005), foi introduzido por Yamada et al. (1994) e Entani et al. (2002). Nessa abordagem busca-se a pior eficiência relativa que pode ser atribuída a cada unidade estudada e para isso é feita uma troca dos insumos pelos produtos. Portanto, Entani et al. (2002) definem a fronteira invertida como uma avaliação pessimista e a fronteira eficiente, como otimista. Daí, Azizi (2011) denomina as unidades produtivas na fronteira invertida de: ineficiente-pessimistas. Já aquelas que não se encontram nessa fronteira são denominadas: não ineficientepessimistas.

Conforme a Figura 2, a ineficiência das unidades é avaliada definindo-se um contorno a partir da combinação linear das piores práticas empiricamente observadas. Segundo Silveira et al. (2011) as projeções das unidades produtivas na fronteira invertida indicam um antialvo, ou seja, um anti-Benchmark.

Geralmente, as duas abordagens (otimista e pessimista) devem ser ponderadas, já que a consideração de apenas uma delas pode fornecer resultados tendenciosos. Para medir o desempenho global, Leta et al. (2005) utilizaram um índice de eficiência composto, conforme 3, do qual deduzem que para maximizar a eficiência composta, a unidade precisa ter bom desempenho na fronteira eficiente (padrão) e um desempenho ruim na fronteira invertida. Assim, a unidade mais eficiente é aquela que conseguir um desempenho mais equilibrado, ou seja, é aquela que produzir muito de todos os produtos com os recursos dados. Nesse caso, a eficiência composta tentará excluir do grupo de eficientes as unidades que foram consideradas eficientes graças ao bom desempenho em apenas um único produto.

$$
\text { Eficiência composta }=\frac{\text { eficiência padrão }+(1-\text { eficiência invertida })}{2}
$$

\section{Parâmetros para estimar a eficiência}

O ensino infantil e fundamental são etapas da educação básica e competências dos municípios, que somente podem atuar em outros níveis de ensino quando 


\section{Produto 2/Insumo}

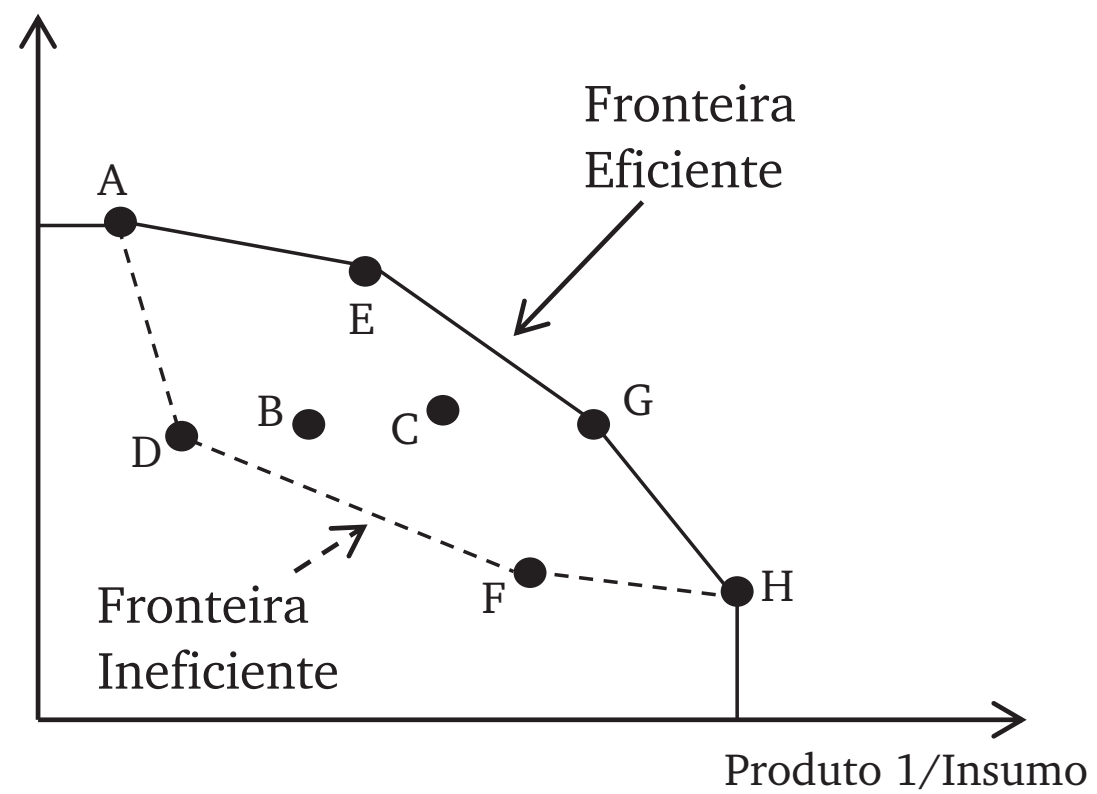

Fonte: Adaptado de Entani et al. (2002).

Figura 2: Fronteira DEA clássica e invertida

estiverem atendidas plenamente as necessidades dos primeiros. A educação infantil não é obrigatória, porém sim, direito da criança, opção da família e dever do município. A educação fundamental é obrigatória, gratuita (nas escolas públicas), e atende crianças com idade entre 6 e 14 anos. Ela divide-se, na prática, em dois ciclos. O primeiro corresponde aos primeiros quatro anos (chamados anos iniciais); o segundo, aos anos finais, demanda que em municípios pequenos é atendida principalmente pela rede estadual de educação. Com a Lei 11.274, de 6 de fevereiro de 2006 que regulamenta o ensino fundamental de 9 anos, os anos iniciais - faixa etária de 6 a 10 anos de idade passam a ter uma duração de 5 anos; os anos finais — faixa etária de 11 a 14 anos de idade - duração de 4 anos.

Segundo o Censo Escolar, a rede pública municipal em Goiás, em 2008, contava com 2.377 estabelecimentos de ensino, tinha 14.889 salas de aulas e 610.138 alunos, sendo que $17 \%$ estão na educação infantil, $58 \%$ nos anos iniciais do ensino fundamental, $20 \%$ nos anos finais e $5 \%$ na educação de jovens e adultos. Esse número corresponde a $42 \%$ do total de alunos do ensino básico em Goiás (INEP 2009a).

Este estudo exploratório sobre o desempenho das redes municipais de ensino exige, inicialmente, a definição de um modelo conceitual que permita explicar seu funcionamento. Neste trabalho, a educação é contemplada como qualquer outra função de natureza produtiva, representada pela relação técnica entre um conjunto de fatores produtivos (insumos) que se combinam adequadamente para obter certos resultados (produtos). Daí, foram selecionadas as variáveis que influenciam, determinam e representam os resultados escolares: o entorno escolar, os insumos e produtos do modelo.

Como em outros países, a variância do desempenho entre as escolas brasileiras deve-se entre outras causas a diferenças do o entorno escolar (Albernaz et al. 2002). Conforme foi discutido anteriormente, ele geralmente é carac- 
terizado por um conjunto de elevado número de variáveis não controláveis de natureza individual, econômica, social e cultural. Dada à indisponibilidade dessa informação, em alguns trabalhos utilizam-se variáveis aproximadas (proxies). Por exemplo, nos trabalhos de Bessent et al. (1982) e de Thanassoulis \& Dustan (1994), estima-se o nível econômico das famílias dos alunos a partir da percentagem de alunos com direito a desconto no almoço escolar. Neste trabalho, utiliza-se o Índice FIRJAN de Desenvolvimento Municipal IFDM de 2006. Ele sintetiza adequadamente o entorno diferenciado das redes municipais de ensino e está correlacionado com muitos insumos não controláveis.

Os insumos considerados foram os gastos municipais com:

1. Recursos humanos, definidos como as despesas com pessoal ativo e encargos sociais;

2. Outras despesas correntes, entendidas como as despesas com a manutenção e funcionamento da rede escolar;

3. Investimentos, caracterizados como os desembolsos de capital destinados ao planejamento e à execução de obras públicas e à aquisição de instalações, equipamento e material permanente.

Esses dados foram obtidos dos Relatórios Municipais do Sistema de Informações sobre Orçamentos Públicos em Educação (SIOPE 2010).

No que se refere à escolha dos produtos, é necessário enfatizar que esta tarefa se torna complexa, devido às dificuldades encontradas na delimitação da natureza multidimensional e global dos objetivos educacionais. Por esse motivo, uma prática habitual encontrada nas pesquisas empíricas é a seleção de variáveis que expressem os resultados primordiais, porém intermediários (não finais), da educação: os rendimentos escolares. Assim, os produtos das redes municipais selecionados foram:

1. Taxas de aprovação na $4^{\mathrm{a}}$ série;

2. Taxas de aprovação na $8^{\mathrm{a}}$ série;

3. Notas padronizadas em Língua Portuguesa e Matemática da Prova Brasil na $4^{\circ}$ série;

4. Notas padronizadas em Língua Portuguesa e Matemática da Prova Brasil na $8^{\circ}$ série;

5. Número de matrículas na educação infantil, especial, de jovens e adultos e convencional no ensino fundamental.

Os dois primeiros produtos mensuram a natureza qualitativa e evidenciam os níveis de reprovação e abandono escolar; os restantes, os aspectos quantitativos. As informações sobre os produtos foram obtidas da página web do Instituto Nacional de Estudos e Pesquisas Educacionais Anísio Teixeira INEP $(2010,2009 c)$. Nos poucos casos de ausência de dados foram utilizadas as médias da rede pública.

Os valores dos insumos e produtos resultaram das médias dos resultados dos anos 2005, 2007 e 2009 e dessa forma, conseguiu-se contemplar os 246 
municípios goianos. Esses valores indicam que tanto os gastos públicos municipais em educação quanto os resultados escolares avançaram expressivamente e mostraram uma correlação positiva entre os produtos e insumos (Tabela 1$)$.

As variáveis selecionadas permitem calcular e georreferenciar os índices de eficiências adotando os seguintes passos metodológicos:

1. inicialmente escolheram-se os modelos CCR com os dados originais independentemente das condições do contexto não controlável, mas devido à diferença de tamanho entre os municípios goianos e aos retornos marginais decrescente da função produção; os modelos BCC foram usados também para verificar se as redes municipais de ensinos estão maximizando a produção escolar e determinar o porte ideal desses serviços;

2. seguidamente aplicou-se o modelo Fried-Lovell e calcularam-se os valores corrigidos. Como já explicado, é necessário isolar o impacto das variáveis não controláveis caracterizadas pelo IFDM. Os gestores escolares municipais não podem ser responsabilizados por ineficiências que, em parte, incorporam influências negativas não controláveis por eles;

3. a partir dos resultados anteriores, aplicou-se o método da fronteira invertida, e em seguida calculou-se a eficiência composta, que finalmente passou a ser padronizada dividindo-se cada resultado pelo maior valor encontrado. Isto foi feito porque a especialização em alguns produtos em detrimento de outros é indesejada.

\section{Resultados}

De acordo com os passos metodológicos descritos, a Tabela 2 ilustra os resultados obtidos para as eficiências das 246 redes municipais de ensino para o período analisado, subdivididos em quatro categorias.

Os resultados revelam que a média geométrica dos índices de eficiência global dos municípios no período com o modelo CCR-OO foi de 1,48, o que indica que, no período em análise, se todas as redes municipais tivessem adotado as melhores práticas e atuado no mesmo contexto, poderia se obter com os mesmos recursos, um resultado maior em $48,28 \%$, no mínimo.

O nível de ineficiência global com o modelo CCR-IO é de 67,44\%. A distribuição espacial desses índices se observa na Figura 3, indicando que apenas 20 municípios são eficientes. Três causas explicam esse resultado: a) ineficiência de escala, b) impacto do entorno, c) ineficiência de gestão.

A ineficiência de escala (o porte inadequado) é responsável por 11,63\% da ineficiência global $(79,07-67,44)$, identificando-se 43 municípios prestando serviços com escalas produtivas subdimensionadas, $183 \mathrm{com}$ escalas superdimensionadas e 20 com o porte ideal conforme Figura 4. Isso sugere dois tipos de reestruturações que podem elevar a eficiência escolar: 1) as redes municipais superdimensionadas podem reorganizar-se descentralizando e criando unidades de gestão do porte dos municípios que operam com escala ótima e atendem até 2258 alunos; 2) as subdimensionadas podem associar-se criando consórcios ou sistemas intermunicipais de gestão escolar. No mapa da Figura 3 , observa-se que muitos desses municípios são vizinhos, o que facilitaria a criação dos consórcios. 


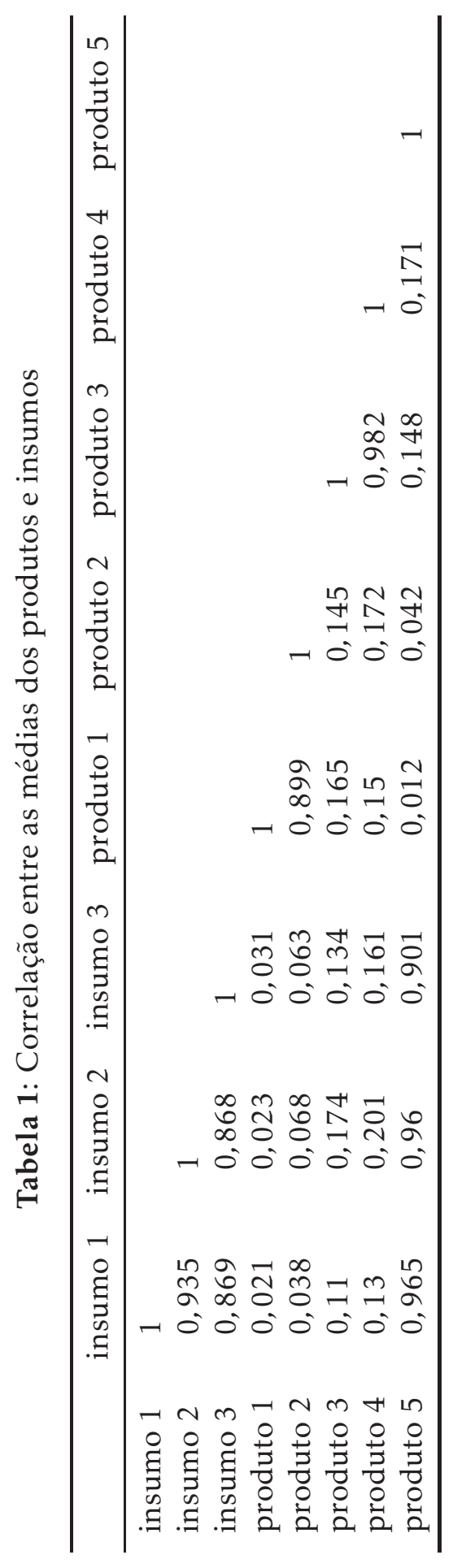


Tabela 2: Estatística Descritiva dos Índices de Eficiência

\begin{tabular}{lcccc}
\hline Estatística resumo & $\begin{array}{l}\text { CCR-OO com } \\
\text { os dados origi- } \\
\text { nais }\end{array}$ & $\begin{array}{l}\text { CCR-IO com } \\
\text { os dados } \\
\text { originais }\end{array}$ & $\begin{array}{l}\text { BCC-IO com } \\
\text { os dados } \\
\text { originais }\end{array}$ & $\begin{array}{l}\text { BCC-IO com } \\
\text { os dados } \\
\text { corrigidos }\end{array}$ \\
Média Geométrica & 1,4828 & 0,6744 & 0,7907 & 0,8308 \\
Média Aritmética & 1,5689 & 0,7010 & 0,8079 & 0,8467 \\
Desvio padrão & 0,7418 & 0,1774 & 0,1615 & 0,1563 \\
Mínimo & 1,0000 & 0,1110 & 0,4270 & 0,4670 \\
Máximo & 9,0080 & 1,0000 & 1,0000 & 1,0000 \\
\hline
\end{tabular}

O impacto do entorno não controlável explica 4,01\% da ineficiência global $(83,08-79,07)$. Isso mostra que políticas voltadas para melhorar os indicadores da escolaridade do chefe de família, da renda e saúde familiar, sintetizados no índice de desenvolvimento municipal - IFDM, podem aumentar a eficiência escolar. Esse dado também é confirmado por informações apontadas por outras pesquisas sobre os impactos das políticas de transferência de renda, expressas pelo Programa Bolsa Família (PBF), na melhora no rendimento escolar. Por exemplo, os resultados de Glewwe \& Kassouf (2008) mostraram que, de 1998 a 2005 , o PBF aumentou as matrículas de $1^{\text {a }}$ a $4^{\text {a }}$ série em $5,5 \%$ e de $5^{\mathrm{a}}$ a $8^{\text {a }}$ série em $6,5 \%$, diminuiu as taxas de abandono escolar em $0,5 \%$ de $1^{\text {a }}$ a $4^{\mathrm{a}}$ série e em $0,4 \%$ nas de $5^{\mathrm{a}}$ a $8^{\mathrm{a}}$ série e aumentou as taxas de aprovação em cerca de $0,9 \%$ de $1^{\text {a }}$ a $4^{\text {a }}$ série e $0,3 \%$ de $5^{\text {a }}$ a $8^{\mathrm{a}}$ série.

Depurando o efeito negativo do entorno e da escala, observa-se que a ineficiência da gestão é responsável por $16,92 \%$ da ineficiência global (100-83,08). Como registrado na Figura 5, o número de municípios com ineficiência de gestão é alto (165) e a dispersão desse índice - muito grande. Portanto, iniciativas voltadas para a troca de experiências, a transferência e difusão das tecnologias educacionais das melhores práticas deverão também induzir uma maior eficiência.

O índice do modelo BCC-IO, ainda, permitiu calcular as mudanças (radiais) necessárias para que as unidades ineficientes superem a ineficiência relativa. Estimou-se que, no período em análise, se as redes municipais tivessem adotado as melhores práticas, poder-se-ia obter os mesmos resultados com uma economia de recursos da ordem de $\mathrm{R} \$ 178.488 .117,59$ (12,2\% do total aplicado). A distribuição espacial dos custos da ineficiência pode ser visualizada na Figura 6.

É importante notar que a grande maioria dos municípios que alcançou os melhores resultados acadêmicos em relação ao valor dos desembolsos efetuados apresentaram indicadores acadêmicos absolutos abaixo da média estadual. Portanto, a alocação de recursos extras nesses municípios eficientes deveria ser prioritária. A probabilidade de esses recursos serem aplicados de forma eficiente e inovadora é maior. Ao mesmo tempo, uma maior alocação de recursos nas redes ineficientes não garante melhores resultados, se antes não se solucionar a ineficiência, ou seja, maiores recursos para unidades ineficientes podem traduzir-se em maiores desperdícios.

Revelando a estrutura benevolente dos métodos clássicos, os índices BCC com os dados corrigidos causam "empates", identificando 81 municípios eficientes no período analisando. O cálculo da eficiência invertida e da eficiência composta permite excluir do grupo de eficientes os municípios que foram considerados eficientes em apenas um único produto, e aponta que a rede de ensino que obteve a atuação mais equilibrada foi Campo Verde. Esse municí- 
pio teve o melhor desempenho no BCC-OO clássico e no IBCC-OO fronteira invertida.

A comparação entre esses resultados, visualizados na Figura 7 e 8, permite observar a severidade do índice de eficiência composta, pois muitos municípios que haviam sido avaliados como eficientes no modelo clássico, tiveram alta ineficiência com a fronteira invertida. Desses, 13 municípios estão localizados tanto na fronteira eficiente quanto na ineficiente, sendo intercessões entre essas duas fronteiras. Esse resultado decorre da especialização em alguns indicadores de desempenho em detrimento de outros.

O cálculo da eficiência invertida, da eficiência composta e do índice de eficiência composta padronizada permite identificar os municípios que merecem maior atenção, ou seja, encontrar os anti-benchmarks. Observa-se que o município de Aloândia teve o pior desempenho nas avaliações realizadas: BCC-OO clássico e IBCC-OO fronteira invertida. Os resultados dos índices de eficiência composta padronizada podem ser vistos na Figura 9, onde se destacam a melhor (Campo Verde) e pior (Aloândia) prática.

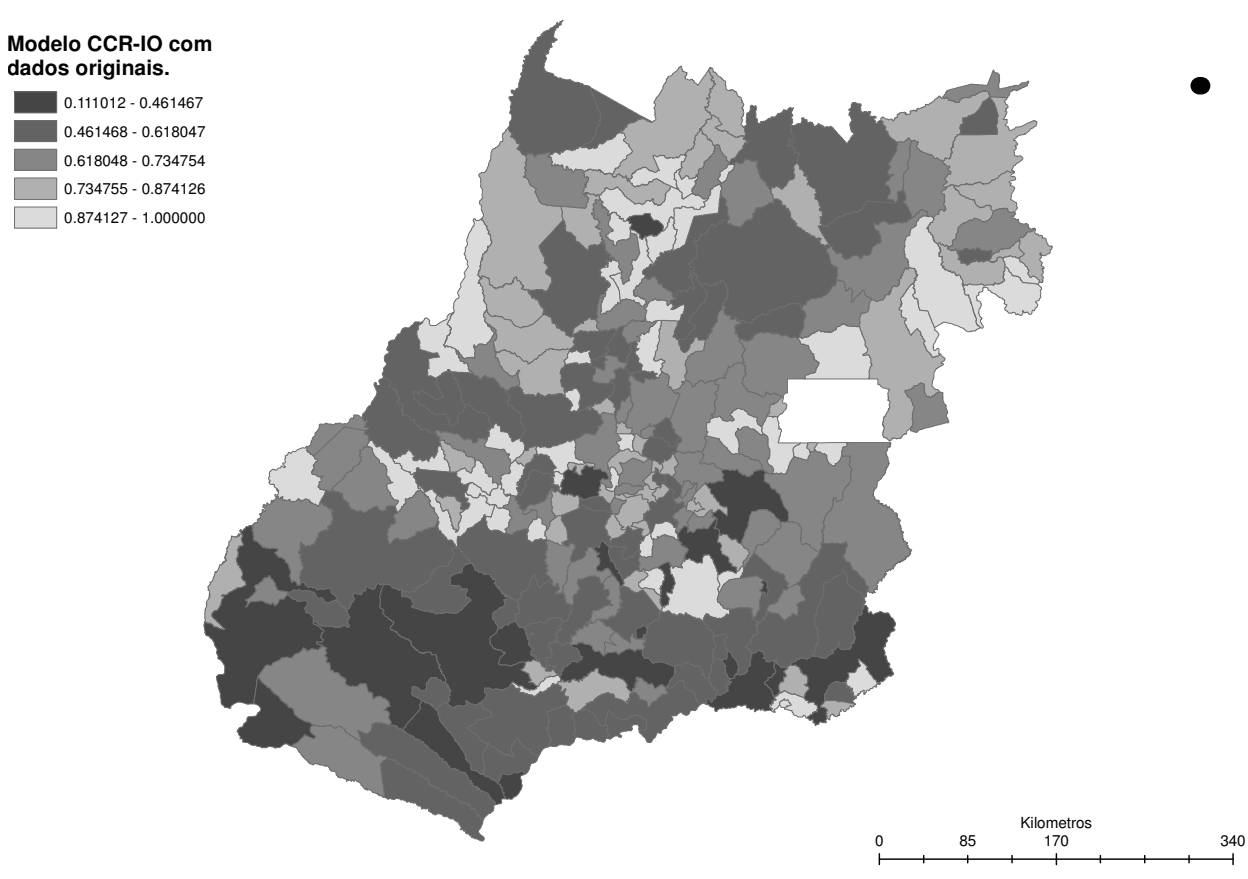

Figura 3: Distribuição espacial dos índices CCR-IO com os dados originais

\section{Conclusões}

Neste trabalho avaliou-se a eficiência dos gastos públicos em educação dos municípios goianos, empregando o método Análise Envoltória de Dados e mapas produzidos em ambiente SIG (Sistemas de Informação Geográfica). O objetivo foi ajudar a suprir uma lacuna importante no que diz respeito à avaliação do desempenho desses municípios.

Os resultados revelam o nível de ineficiência global $(67,44 \%)$ e suas causas, quais são: a) ineficiência de escala (o porte inadequado), b) impacto do entorno não controlável, c) ineficiência de gestão. A ineficiência de escala é 


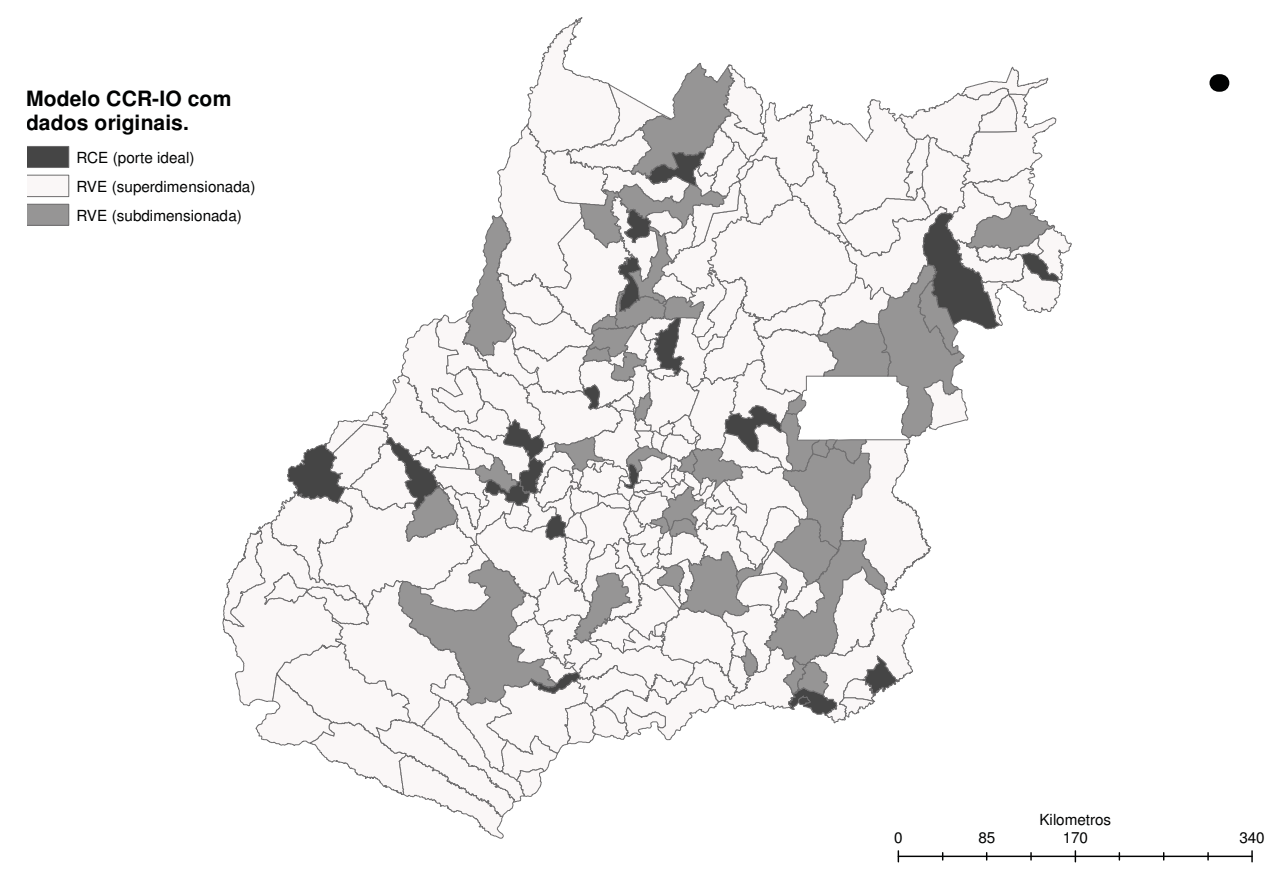

Figura 4: Distribuição espacial da ineficiência de escala com os dados originais

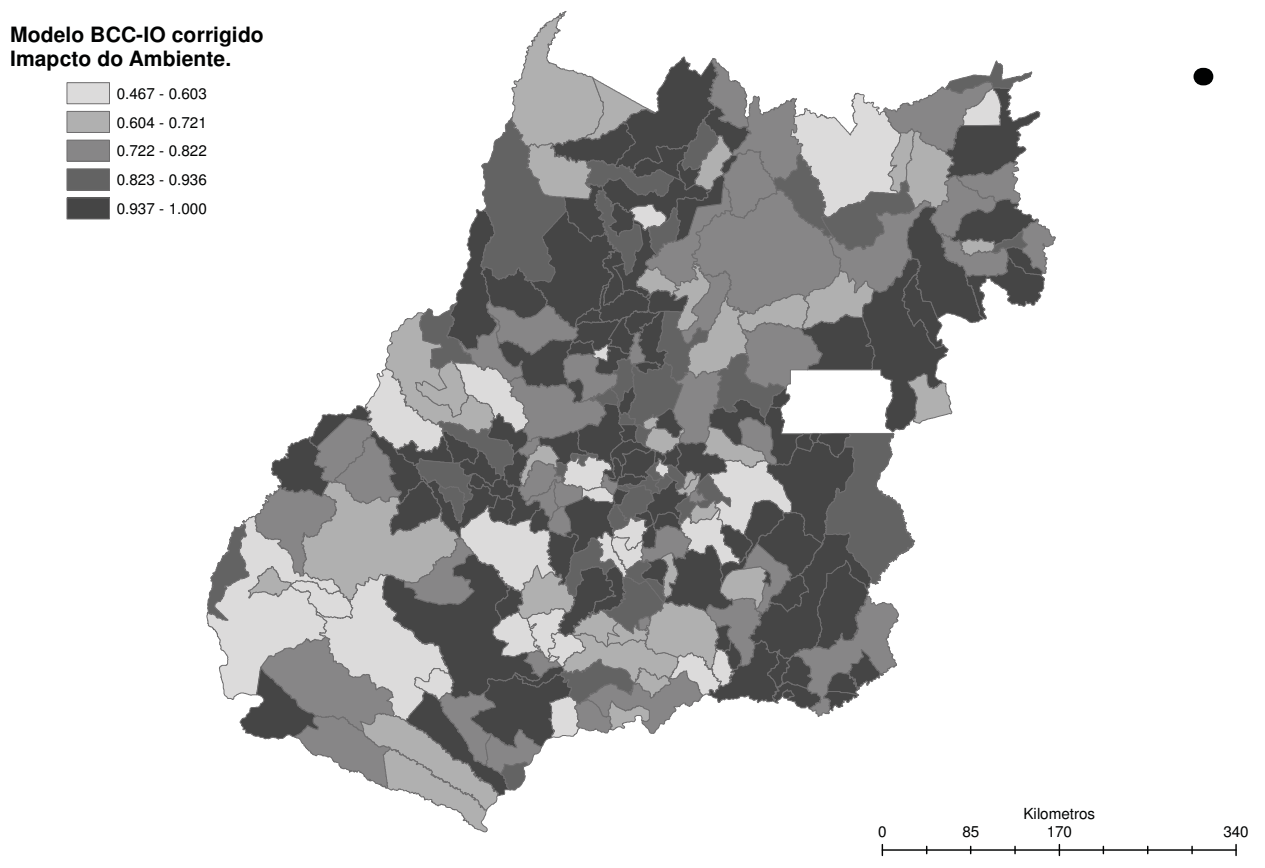

Figura 5: Distribuição espacial dos índices BCC-IO com os dados corrigidos 
Potencial economia de

recursos (custo da ineficiarcia)

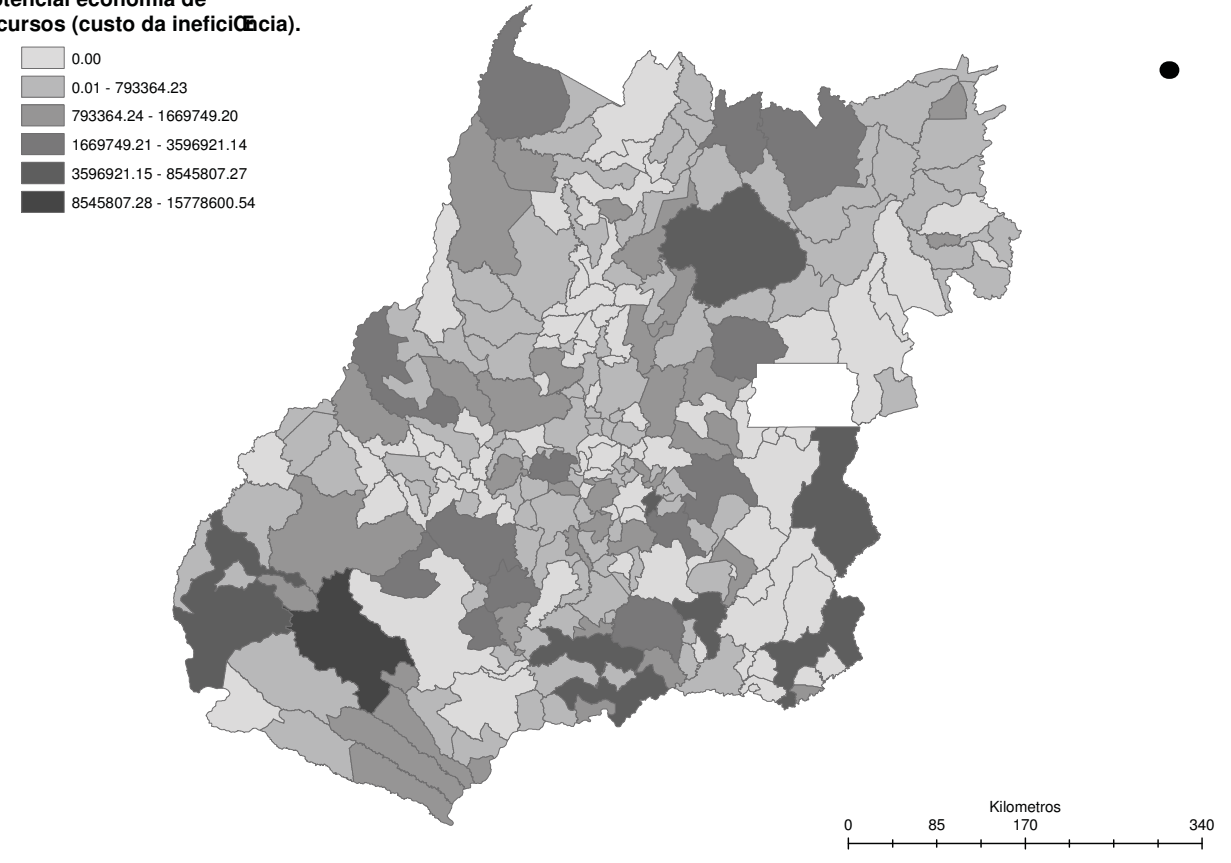

Figura 6: Distribuição espacial dos custos da ineficiência

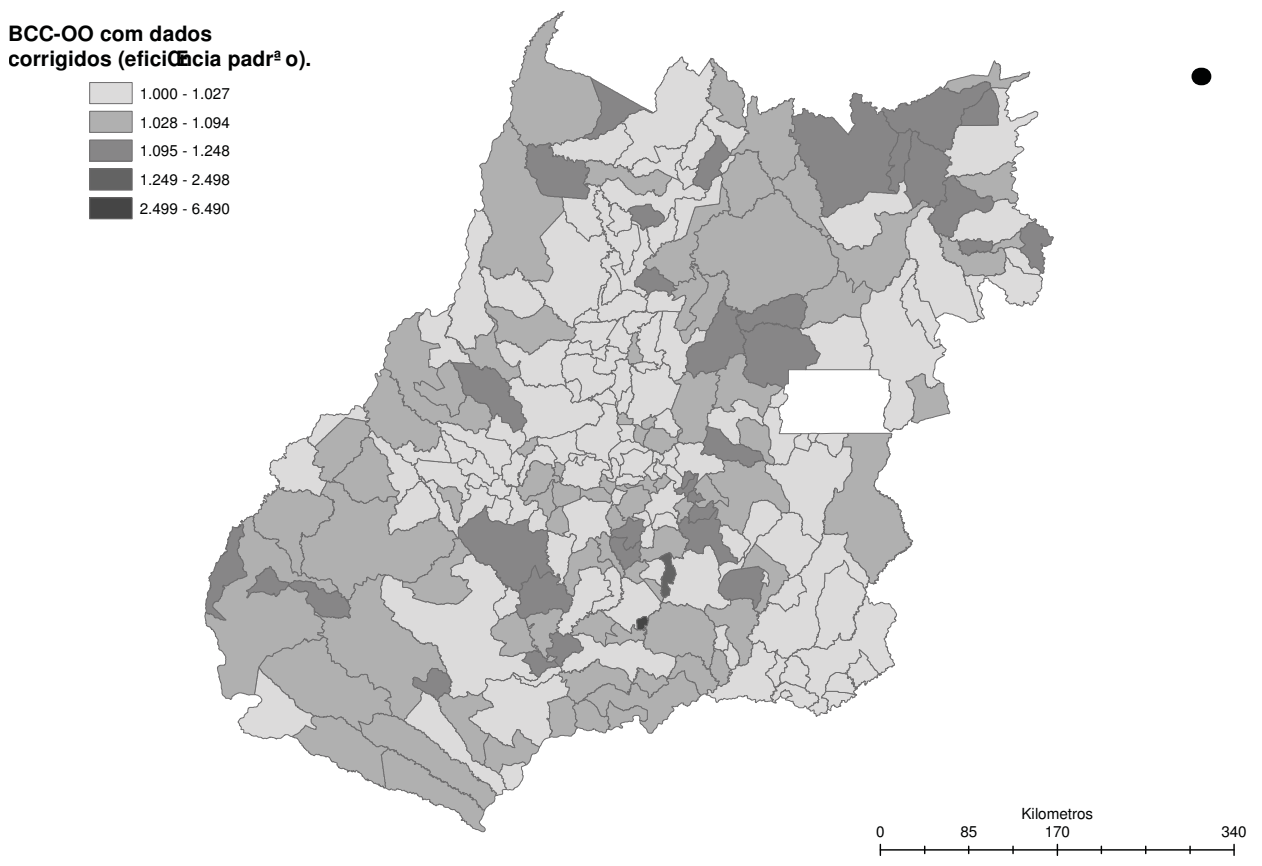

Figura 7: Distribuição espacial dos índices da fronteira padrão 


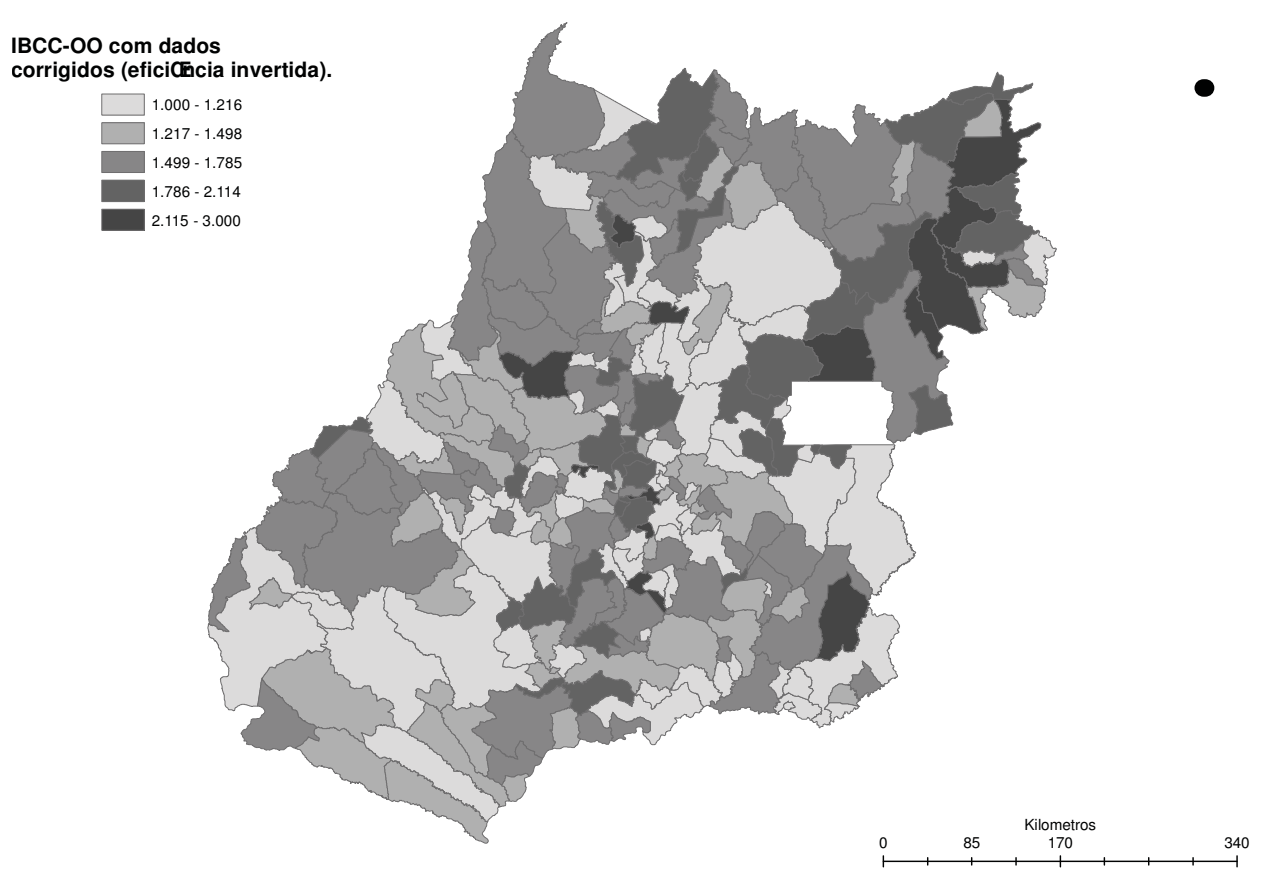

Figura 8: Distribuição espacial dos índices da fronteira invertida

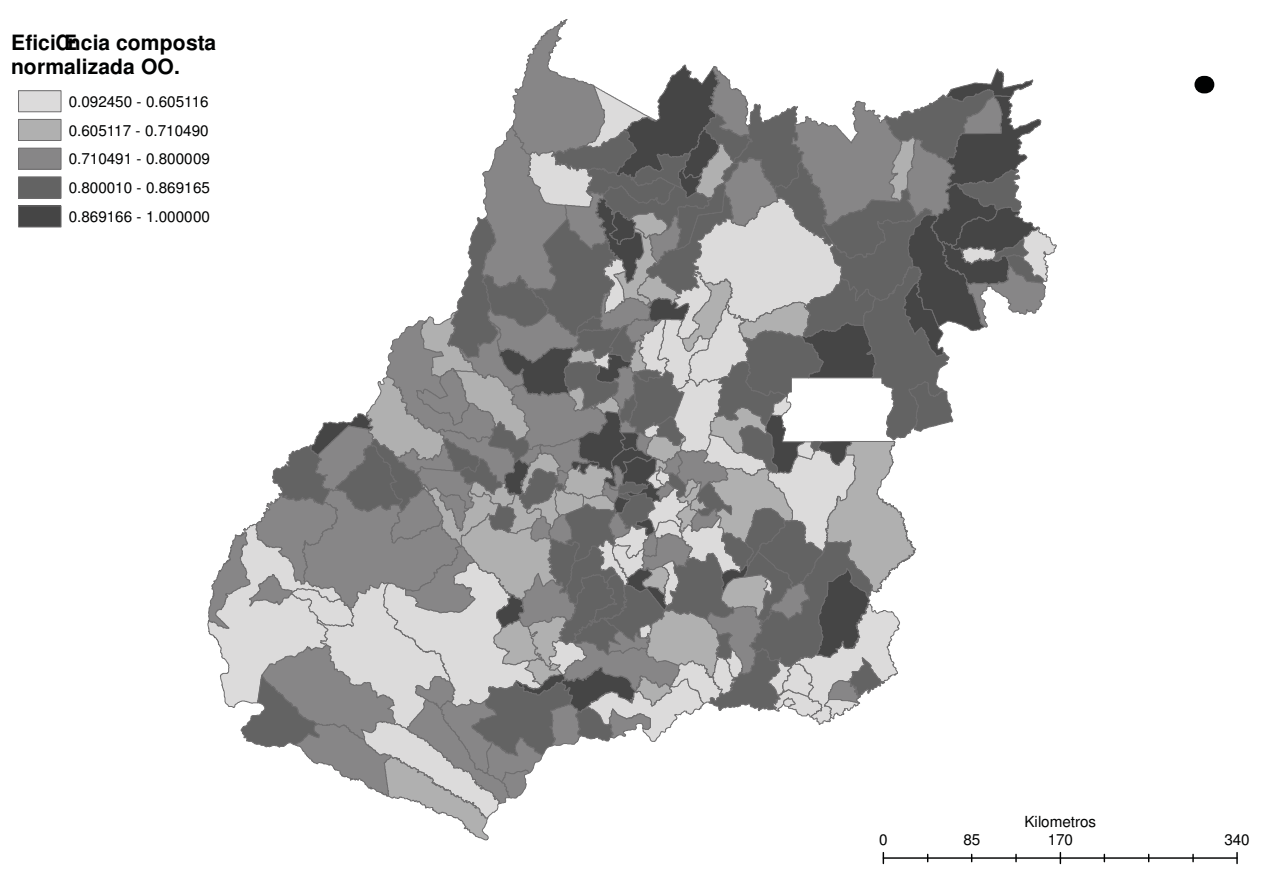

Figura 9: Distribuição espacial dos índices de eficiência composta padronizada 
responsável por $11,63 \%$ da ineficiência global; já o impacto do entorno explica $4,01 \%$ e a ineficiência de gestão explica $16,92 \%$. A partir deste último estimou-se que se, no período em análise, as redes municipais tivessem adotado as melhores práticas, poder-se-ia obter os mesmos resultados com uma economia de recursos da ordem de $\mathrm{R} \$ 178.488 .117,59$. O método utilizado também permitiu identificar e mapear as redes municipais de ensino que conseguiram alcançar o desempenho mais equilibrado, ou seja, aquelas que conseguiram produzir muito de todos os produtos com os recursos dados.

Uma conclusão que se pode tirar da análise realizada é que apesar dos dados mostrarem uma correlação positiva entre os recursos disponibilizados e os resultados educacionais obtidos, essa relação se torna espúria quando existem evidências de ineficiência. A maior alocação de insumos não garante melhores resultados se antes não se solucionar a ineficiência das unidades educacionais. Em outras palavras, maiores recursos para unidades ineficientes podem traduzir-se em maiores desperdícios. Como indicado por diversos autores no estudo de outras regiões, as diferenças nos resultados educacionais dos municípios devem estar principalmente na gestão escolar e nas políticas públicas para gestão escolar (Diaz 2007, Menezes-Filho 2007).

Do mesmo modo, essa conclusão está em consonância com um dos resultados da pesquisa de Ferraz et al. (2009), que analisaram o resultado da auditoria dos gastos de 365 municípios feita pela Controladoria Geral da União (CGU), entre 2001 e 2004 e depois, cruzaram esses dados com o resultado obtido na Prova Brasil pelos alunos da $4^{\mathrm{a}}$ série do ensino fundamental das 1.488 escolas públicas existentes nos municípios analisados. O trabalho mostrou que o desvio e a má gestão dos recursos repassados para as escolas públicas brasileiras têm gerado efeitos danosos para alunos e professores.

É importante destacar, no entanto, que alguns cuidados devem ser tomados na utilização dos resultados encontrados. O DEA, como qualquer outra metodologia, possui limitações. Por ser uma técnica determinística e por ser a eficiência uma medida relativa às melhores práticas amostradas, o DEA é muito suscetível às observações. A análise está condicionada à amostra das unidades avaliadas, às variáveis incluídas na pesquisa e ao princípio de que todos os demais fatores envolvidos são idênticos. O acréscimo ou exclusão de unidades e variáveis podem afetar os resultados.

Para finalizar, cabe destacar também que existe um grande potencial de pesquisa no que se refere à eficiência das redes municipais de ensino no Brasil, já que são poucos os estudos com esse enfoque. Grande parte da avaliação do ensino municipal baseia-se em estatísticas descritivas. Novos estudos podem determinar e modelar os mecanismos implícitos e explícitos de inter-relação espacial da eficiência das redes municipais de ensino. Igualmente, a análise dos índices de eficiência aqui desenvolvida é estática, uma vez que se utilizam variáveis e se comparam unidades num período dado. A introdução de uma dimensão temporal permitirá criar um modelo dinâmico, que desloca a questão central para outros problemas muito importantes: 1) a evolução da produtividade de cada unidade relativamente à evolução do conjunto de unidades avaliadas, 2) a decomposição do índice de produtividade em termos de mudanças tecnológicas, eficiência técnica pura e de escala, 3) a natureza da trajetória temporal, com ou sem flutuações, com tendência a convergir ou divergir. 


\section{Referências Bibliográficas}

Albernaz, A., Ferreira, F. H. G. \& F., C. (2002), 'Qualidade e eqüidade no ensino fundamental brasileiro', Pesquisa e Planejamento Econômico 32(4), 453476.

Azizi, H. (2011), 'The inverval efficiency based on the optimistic and pessimistic points of view', Applied Mathematical Modelling 35, 2384-2393.

Banker, R., Charnes, A. \& Cooper, W. (1984), 'Some models for estimating technical and scale inefficiencies in data envelopment analysis', Management Science 30(9), 1078-1092.

Bessent, A. M., Bessent, E. W., Kennington, J. \& Reagan, B. (1982), 'An application of mathematical programming to assess productivity in the houston independent school district', Management Science 28(12), 1355-1367.

Carvalho, M. d. (2002), Cidadania no Brasil: o longo caminho, edição edn, Rio de Janeiro:Civilização Brasileira.

Charnes, A., Cooper, W. W. \& Rhodes, E. (1979), 'Measuring the efficiency of decision-making units', European Journal of Operational Research 3(4), 339338.

Coleman, J. S. (1966a), 'Equality of educational opportunity', Washington, D.C.: U.S. Government Printing Office .

Coleman, J. S. (1966b), 'Equality of educational opportunity', Washington, D.C.: U.S. Government Printing Office .

Delgado, V. M. S. \& Machado, A. F. (2007), 'Eficiência das escolas públicas estaduais de minas gerais', Pesquisa e Planejamento Econômico 37(3).

Diaz, M. D. M. (2007), 'Qualidade do gasto público em educação no brasil. in: Qualidade do gasto público no brasil: sugestões para melhorar os resultados das políticas públicas, sem aumento de impostos', Organisation for Economic Co-operation and Development - OECD. Fundação Instituto de Pesquisas Econômicas - FIPE. S.P.

Entani, T., Maeda, Y. \& Tanaka, H. (2002), 'Dual models of interval dea and its extensions to interval data', European Journal of Operational Research 136, 32-45.

Fare, R., Grosskopf, S., Forsund, F., Hayes, K. \& Heshmati, A. (2006), 'Measurement of productivity and quality in non-marketable services: With application to schools', Quality Assurance in Education 14(1), 21-36.

URL: $\quad h t t p: / / w w w . i n g e n t a c o n n e c t . c o m / c o n t e n t / m c b / 120 / 2006 / 00000014 /-$ 00000001/art00001

Faria, A. F. \& Januzzi, P. M. (2006), 'Eficiência dos gastos municipais em saúde e educação: uma investigação através da análise envoltória no estado do rio de janeiro', Rio de Janeiro: Ipea, (Prêmio Ipea-Caixa 2006; Concurso de Monografias. Tema 1: Eficiência e Efetividade do Estado no Brasil). 
Façanha, L. \& Marinho, A. (1999), 'Instituições federais de ensino superior: modelos de financiamento e o incentivo à eficiência', Revista Brasileira de Economia 53(3), 357-386.

Façanha, L. \& Marinho, A. (2001), 'Instituições de ensino superior governamentais e particulares: avaliação comparativa de eficiência [texto para discussão]', Rio de Janeiro: Ipea (813).

Ferraz, C., Finan, F. \& Moreira, D. (2009), 'Corrupting learning: Evidence from missing federal education funds in brazil'.

URL: http://www.econ.puc-rio.br/pdf/td562.pdf Acessado em 11/06/2011

Franco, A. M. P. (2008), 'Os determinantes da qualidade da educação no brasil', Tese Doutorado em Economia. Universidade de São Paulo, SP.

Fried, H. O. \& Lovell, C. A. K. (1996), 'Searching for the zeds', II Georgia Productivity Workshop.

Fried, H. O., Lovell, C. A. K., Schmidt, S. S. \& Yaisawarng, S. (2002), 'Accounting for environmental effects and statistical noise in data envelopment analysis'.

URL: http://espace.library.uq.edu.au/view/UQ:193814

Fried, H. O., Schmidt, S. S. \& Yaisawarng, S. (1999), 'Incorporating the operating environment into a nonparametric measure of technical efficiency', Journal of Productivity Analysis 12, 249-267.

Gasparini, C. E. \& Ramos, F. S. (2003), 'Efetividade e eficiência no ensino médio brasileiro', Economia Aplicada 7(2), 389-411.

Glewwe, P. \& Kassouf, A. L. (2008), 'O impacto do programa bolsa familia no total de matrículas do ensino fundamental, taxas de abandono e aprovação'. Prêmio Nacional de Estudos sobre a Bolsa Família - 2008.

URL: $\quad h t t p: / / w w w . c e p e a . e s a l q . u s p . b r / p d f / C e p e a \_I m p a c t o B o l s a F a m i l i a-$ _Premio.pdf

Gyimah-Brempong, K. \& Gyapong, A. O. (1991), 'Characteristics of education production functions: An application of canonical regression analysis', Economics of Education Review 10(1), 7-17.

Hanushek, E. A. \& Luque, J. (2002), 'Efficiency and equity in schools around the world', [Working papers, n. 8.949]. Cambridge, Mass: National Bureau of Economic Research p. 42 p.

INEP (2009a), 'Censo escolar', Instituto Nacional de Estudos e Pesquisas Educacionais Anísio Teixeira.

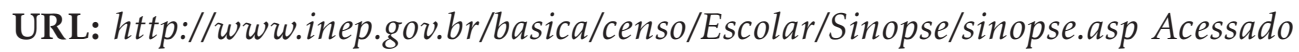
em 22/05/2010

INEP (2009b), 'Investimentos públicos em educação', Instituto Nacional de Estudos e Pesquisas Educacionais Anísio Teixeira.

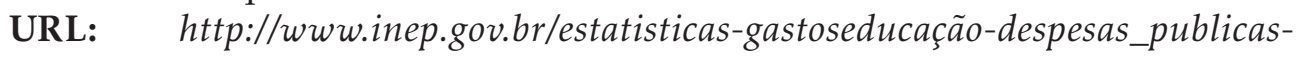
p.a._paridade.htm Acessado em 22/05/2010 
INEP (2009c), 'Investimentos públicos em educação', Instituto Nacional de Estudos e Pesquisas Educacionais Anísio Teixeira. Censo Escolar.

URL: http://www.inep.gov.br/basica/censo/Escolar/Matricula/censoescolar Acessado em 22/05/2010

INEP (2010), 'Investimentos públicos em educação', Instituto Nacional de Estudos e Pesquisas Educacionais Anísio Teixeira. Estatísticas do Ideb.

URL: http://portalideb.inep.gov.br/planilhas-para-download Acessado em $22 / 05 / 2010$

Leta, F., Mello, J. d., Gomes, E. \& Meza, L. (2005), 'Métodos de melhora de ordenação em dea aplicados à avaliação estática de tornos mecânicos', Investigação Operacional, Lisboa 25(2), 229-242.

Marinho, A., Resende, M. \& Façanha, L. O. (1997), 'Brazilian federal universities: relative efficiency evaluation and data envelopment analysis', Revista Brasileira de Economia 51(4), 489-508.

Menezes-Filho, N. A. (2007), Os determinantes do desempenho escolar no brasil, in '[Texto para discussão]. São Paulo', Instituto Futuro Brasil, p. 30 p.

Muniz, M. (2001), 'Introducción de variables de control en modelos dea', In A. Álvarez (Ed.). La Medición de la eficiencia y la productividad. Madrid: Ed. Pirámide.

Muniz, M. (2002), 'Separating managerial inefficiency and external conditions in data envelopment analysis', European Journal of Operational Research 143(3), 625-643.

URL: $\quad$ http://www.ingentaconnect.com/content/els/03772217/2002/00000143/00000003/art00344

OECD (2007), 'Education at a glance 2007. oecd indicator', Organisation for Economic Co-operation and Development - OECD.

URL: $\quad h t t p: / / w w w . o e c d . o r g / d a t a o e c d / 4 / 55 / 39313286 . p d f$ Acessado em 22/08/2010

OECD (2010), 'Pisa 2009 results: Executive summary', Organisation for Economic Co-operation and Development - OECD.

URL: $\quad h t t p: / / w w w . o e c d . o r g / d a t a o e c d / 34 / 60 / 46619703 . p d f$ Acessado em $22 / 05 / 2011$

Pedraja-Chaparro, F. anda Salina-Jiménez, J. \& Suárez-Pandiello, J. (2001), La Medición de la eficiencia en el sector público. In A. Álvarez (Ed.) La Medición de la eficiencia y la productividad, edição edn, Madrid: Ed. Pirámide.

Pontili, R. M. \& Kassouf, A. L. (2007), 'Fatores que afetam a frequência e o atraso escolar, nos meios urbano e rural, de são paulo e pernambuco', Revista de Economia e Sociologia Rural 45(1), 27-47.

Portela, M. \& Thanassoulis, E. (2001), 'Decomposing school and school-type efficiency', European Journal of Operational Research 132(2), 357-373.

URL: $h t t p: / / w w w . s c i e n c e d i r e c t . c o m / s c i e n c e / a r t i c l e / p i i / S 0377221700001570$

Ruggiero, J. (1996), 'Efficiency of educational production: An analysis of new york school districts', The Review of Economics and Statistics 78(3), 499-509.

URL: http://www.jstor.org/stable/2109797 
Ruggiero, J. (2006), 'Measurement error, education production and data envelopment analysis', Economics of Education Review 25(3), 327-333.

URL: $h t t p: / / i d e a s . r e p e c . o r g / a / e e e / e c o e d u / v 25 y 2006 i 3 p 327-333 . h t m l$

Scorzafave, L. G. \& Ferreira, R. A. (2011), 'Desigualdade de proficiência no ensino fundamental público brasileiro: Uma análise de decomposição', Economia Aplicada 12(2), 337-359.

Silveira, J., Meza, L. A. \& Soares de Mello, J. (2011), 'Identificação de benchmarks e anti-benchmarks para companhias aéreas usando modelos dea e fronteira invertida', Produção [online] 26, 24-31.

SIOPE (2010), 'Sistema de informações sobre orçamentos públicos em educação - siope (2010)', Relatórios Municipais.

URL: http://www.fnde.gov.br/siope/dadosInformadosMunicipio.do Acessado em $22 / 03 / 2011$

Soares de Mello, J., Meza, L., Gomes, E. \& Bioni Neto, L. (2005), 'Curso de análise de envoltória de dados', In Anais XXXVII Simpósio Brasileiro de Pesquisa Operacional (SBPO), Gramado: RS .

Sousa, M. \& Stosic, B. (2005), 'Technical efficiency of the brazilian municipalities: Correcting nonparametric frontier measurements for outliers', Journal of Productivity Analysis 24(2), 157-181.

Thanassoulis, E. \& Dustan, P. (1994), 'Guiding schools to improved performance using data envelopment analysis: an illustration with data from a local education authority', Journal of the Operational Research Society 45(11), 1247-1262.

UNICEF (2009), 'O direito de aprender: Potencializar avanços e reduzir desigualdades', Fundo das Nações Unidas para a Infância - UNICEF. Coordenação geral Maria de Salete Silva e Pedro Ivo Alcântara - Brasília, DF: UNICEF.

URL: $\quad h t t p: / / w w w . u n i c e f . o r g / b r a z i l / p t / s i a b \_c a p i t u l o s . p d f$ Acessado em $22 / 06 / 2010$

Vinod, H. D. (1976), 'Canonical ridge and econometrics of joint production', Journal of Econometrics 4(2), 147-166.

Worthington, A. (2001), 'An empirical survey of frontier efficiency measurement techniques in education', Education Economics 9(3), 245-268.

Yamada, Y., Matui, T. \& Sugiyama, M. (1994), 'New analysis of efficiency based on dea', Journal of the Operations Research Society of Japan 37, 158-167.

Álvarez, A. (2001), 'La medición de la eficiencia y la productividad', Madrid: Ed. Pirámide. 